\title{
Produção do cuidado em Saúde Mental: \\ desafios para além dos muros institucionais
}

\author{
Thayane Pereira da Silva Ferreira(a) \\ Juliana Sampaio(b) \\ Adelle Conceição do Nascimento Souza(c) \\ Dilma Lucena de Oliveira(d) \\ Luciano Bezerra Gomes ${ }^{(\mathrm{e})}$
}

Ferreira TPS, Sampaio J, Souza ACN, Oliveira DL, Gomes LB. Care production in Mental Health: the challenges beyond institutional walls. Interface (Botucatu). 2017; 21(61):373-84.

The paper puts forward a problematization on the challenges of deinstitutionalization of mental health care from a Psychosocial Care Center (CAPS) in João Pessoa, Brazil. The methodological approach was built in the day-by-day of the service, in which researchers participated in team meetings and accompanied the production of care within and outside the CAPS. In this continuing education process with the CAPS team it has been possible to visualize three movements: The invisibility of the "living territory" in the production on the care networks; the need for matrix support as an articulator of actions of CAPS and primary care, and the deadlocks for deinstitutionalization of life. Finally, we trust that along the movement of opening to the living world of the city, the mental health care could produce care beyond the psychological distress, engaging with the production of life.

Keywords: Deinstitutionalization. Mental health. Psychiatric reform.
O artigo traz algumas problematizações sobre os desafios da desinstitucionalização no cuidado em saúde mental a partir de um Centro de Atenção Psicossocial (CAPS) de João Pessoa, Brasil. O percurso metodológico se deu no cotidiano do serviço, no qual os pesquisadores participavam das reuniões de equipe e acompanhavam a produção do cuidado dentro e fora do CAPS. No processo de educação permanente junto à equipe do CAPS, foi possível produzir visibilidade a três movimentos: a invisibilidade do território vivo na produção das redes de cuidado; a necessidade do matriciamento como articulador das ações do CAPS e a atenção básica; e os impasses para a desinstitucionalização da vida. No entanto, apostamos que, no movimento de abrir-se ao mundo vivo da cidade, a saúde mental consiga produzir cuidados para além do sofrimento psíquico, se ocupando com a produção de vida das pessoas.

Palavras-chave: Desinstitucionalização. Saúde mental. Reforma psiquiátrica.

\footnotetext{
(a) Departamento de Terapia Ocupacional, Centro de Ciências da Saúde, Universidade Federal da Paraíba, Cidade Universitária. João Pessoa, PB, Brasil. 58051-900. thayane.silva01@ hotmail.com

${ }_{(b, d, e)}$ Departamento de Promoção da Saúde, Centro de Ciências Médicas, UFPB. João Pessoa, PB, Brasil. julianasmp@ hotmail.com; dilmalu_jp@ yahoo.com.br; lucianobgomes@ gmail.com

(c) Psicóloga. João Pessoa, PB, Brasil. adellenascimento@ gmail.com
} 


\section{Introdução}

A reforma psiquiátrica brasileira surge na década de 1970, em consonância com diversos outros movimentos mundiais que vinham ocorrendo à época, na busca de denunciar práticas asilares opressoras e que infligiam os direitos humanos dos usuários no campo da saúde mental' ${ }^{1}$.

O referido movimento é um processo ético, político e social, que busca pautar uma série de ressignificações no modelo de cuidado em saúde mental, afetando trabalhadores, usuários, familiares, gestores, além de significativa interferência no território e no imaginário das pessoas nele inseridas'.

O cuidado passa a ter como premissa a defesa da vida e a percepção dos usuários como cidadãos pertencentes à comunidade. Para tanto, é necessário considerar as conexões relacionais que envolvem o sujeito que é cuidado e entendê-las como produtoras de vida.

Desse modo, a mudança de paradigma advinda da reforma psiquiátrica assume, além de uma dimensão técnica (revisão das práticas de cuidado), uma dimensão cultural, na defesa por uma mudança do valor social da loucura, que permita aos sujeitos vivenciarem e participarem da vida comunitária. Alves ${ }^{2}$ aponta que:

Os indivíduos desenvolvem maneiras peculiares de estarem no mundo e de vivenciarem seus sofrimentos, alegrias, frustrações, vitórias e inseguranças. Da mesma maneira, estabelecem relações com suas experiências de enfermidade que são singulares e sustentadas em determinado campo relacional. (p. 54)

O estabelecimento de um cuidado de base comunitária, considerando os sujeitos e suas conexões no território ${ }^{3}$, vem impulsionando novas respostas à multidimensionalidade dos indivíduos e à complexidade do cuidado. Porém, a produção destas redes de cuidado - que potencializam a atenção às pessoas com transtornos mentais ao ampliarem seus espaços de circulação - se configura como grande desafio dentro da rede de saúde mental ${ }^{4}$.

Os Centros de Atenção Psicossocial (CAPS) surgem nesse processo com o objetivo de viabilizar a desinstitucionalização do cuidado em saúde mental. Estes são definidos como dispositivo estratégico para a reordenação do modelo de atenção em saúde mental, tendo como objetivo: promover e potencializar a contratualidade social do usuário, realizar atendimento clínico, ser ordenador da rede e oferecer apoio matricial em saúde mental para a atenção básica ${ }^{1}$.

O fortalecimento do debate sobre cuidado territorializado passa pelo reconhecimento dos CAPS como dispositivo fundamental e coloca a necessidade de transcender o entendimento de território como mera delimitação de espaços geográficos. Guattari e Rolnik ${ }^{5}$ apontam que:

[...] A noção de território deve ser entendida num sentido muito amplo, que ultrapassa o uso que fazem dele a etologia e a etnologia. Os seres existentes se organizam segundo territórios que os delimitam e os articulam aos outros existentes e aos fluxos cósmicos. O território pode ser relativo tanto a um espaço vivido, quanto a um sistema percebido no seio da qual um sujeito se sente "em casa". O território é sinônimo de apropriação, de subjetivação fechada sobre si mesma. Ele é o conjunto de projetos e representações nos quais vai desembocar, pragmaticamente, toda uma série de comportamentos, de investimentos, nos tempos e nos espaços sociais, culturais, estéticos, cognitivos. (p. 323)

Vincular essa noção de território às práticas cotidianas dos serviços tem sido um grande desafio para a construção de novas formas de cuidado em saúde mental que visem a emancipação dos usuários sob suas próprias vidas, garantindo seu protagonismo e participação cidadã na comunidade.

Alverga e Dimenstein ${ }^{6}$ afirmam que parte desses desafios se deve à permanência dos 'desejos de manicômios' nas práticas e concepções profissionais que, muitas vezes, reproduzem uma atenção à saúde voltada ao isolamento, controle e tutela do outro. As mudanças dessas práticas de cuidado consistem, assim, em ações de agenciamento com o território, identificando as conexões relacionais das pessoas que nele habitam. 
Para Saraceno", "as intervenções devem incorporar em suas estratégias o manejo dos fatores de proteção, que são aqueles que garantem aos sujeitos a possibilidade de viver a vida fora dos circuitos de institucionalização" (p. 13). Isto requer, portanto, uma complexidade das ações ofertadas que evitem o empobrecimento do mundo relacional das pessoas com transtornos mentais e ampliem suas possibilidades de manutenção na vida e na comunidade.

No entanto, alguns autores, como Merhy ${ }^{8}$, sinalizam a dificuldade em ser efetivado esse cuidado no território, o qual, muitas vezes, não extrapola os serviços substitutivos, já que "estes não conseguem abarcar a dimensão dos processos relacionais que acontecem no cotidiano das pessoas" (p. 17), o que causaria a manutenção de um cuidado ainda institucional.

Assim, pensar o cuidado em saúde mental como um acontecimento que produz vida e gera possibilidades de inserção do indivíduo na comunidade tem sido uma pauta importante no debate atual sobre a necessidade de mudanças de paradigmas no campo da saúde. Merhy ${ }^{9}$ afirma que:

Os modelos de atenção comprometidos com a vida devem saber explorar positivamente as relações entre as diferentes dimensões tecnológicas \{leve, leve- dura e dura\} que comporta o cuidado, possibilitando a precedência do mundo das necessidades de saúde dos usuários e o reconhecimento de que a saúde é um valor de uso único e inestimável. (p. 16)

Acreditando na importância de se transporem os desafios da produção do cuidado em saúde mental e se potencializar, cada vez mais, um cuidado territorializado é que se localiza o debate deste artigo. Tendo em vista que as redes de cuidado são cotidianamente operadas pelos trabalhadores na micropolítica do trabalho em saúde ${ }^{8}$, o desenvolvimento de processos avaliativos nessas redes de saúde tem se mostrado imprescindível, a partir do entendimento de como ele é produzido em ato.

Nesta direção, tem sido desenvolvida, pela Linha de Pesquisa Micropolítica do Trabalho e o Cuidado em Saúde, a pesquisa: Observatório Nacional da Produção de Cuidado em diferentes modalidades à luz do processo de implantação das Redes Temáticas de Atenção à Saúde no Sistema Único de Saúde: avalia quem pede, quem faz e quem usa, com o objetivo de avaliar a produção do cuidado nas redes temáticas propostas pelo Ministério da Saúde. Em João Pessoa, a pesquisa é desenvolvida por: professores da Universidade Federal da Paraíba, profissionais e gestores, analisando cinco redes temáticas. Dentre elas, a Rede de Atenção Psicossocial (RAPS). Nesta direção, o presente estudo apresenta algumas problematizações, que vêm sendo produzidas entre pesquisadores, acadêmicos, profissionais de saúde, gestores e usuários, sobre os desafios de se produzir a desinstitucionalização do cuidado em saúde mental a partir dos CAPS.

\section{Percurso metodológico}

No rastreamento de modos de cuidados produzidos na RAPS de João Pessoa, tem se buscado espaços produtores de encontros que permitam a construção de narrativas de profissionais e gestores do campo da saúde mental. Neste percurso, o CAPS tem se apresentado como lócus fértil para tais encontros, já que é um serviço com função de coordenação da RAPS num determinado território, visando a produção de redes de cuidado para pessoas com transtornos psíquicos graves e persistentes. O CAPS que participou da construção deste estudo está habilitado na modalidade III, com funcionamento 24 horas e leitos de atenção à crise ${ }^{3}$. Ele funciona desde $2008 \mathrm{e}$, atualmente, conta com uma equipe multiprofissional de oitenta profissionais, sendo referência para três dos cinco distritos sanitários do município. Durante o período do estudo, a equipe contabilizou cerca de quatrocentos usuários em atendimento/mês.

$\mathrm{Na}$ aproximação com o serviço, foi pactuada a participação dos pesquisadores da universidade nas reuniões de supervisão clínico-institucional que aconteciam quinzenalmente no CAPS. A escolha pelas reuniões de supervisão clínico-institucional se deu em pactuação com a própria equipe do serviço que compreendia tal espaço como dispositivo para a discussão dos processos de trabalho da equipe. Contudo, a partir das afecções produzidas nos encontros com os atores envolvidos nos processos de 
trabalho do CAPS, foi sendo produzida coletivamente uma agenda de trabalho cada vez mais intensa, com acompanhamento, por parte dos pesquisadores da universidade, do cuidado produzido pela equipe do CAPS dentro e fora do serviço.

Em todos os espaços compartilhados, os pesquisadores da universidade buscaram se misturar, intervindo e sugerindo; observando e sendo observados; sendo acolhidos e respeitados, mas, também, criticados quando apresentavam pontos de vistas diferentes aos da equipe do CAPS. Essa in-mundicização ${ }^{10}$, entendida como uma possibilidade de se misturar no mundo pesquisado, rompendo com a suposta neutralidade da cientificidade positivista, se desenvolveu entre os meses de fevereiro a julho de 2015, período no qual foram realizados trinta encontros com profissionais, gestores e usuários do CAPS, com duração média de quatro horas. Toda a vivência foi registrada em diários de campo e/ou gravada (com autorização de todos os presentes), o que possibilitou o resgate da memória e o processamento da experiência.

Atendendo às exigências éticas de pesquisas envolvendo seres humanos, foi solicitada a assinatura do Termo de Consentimento Livre e Esclarecido (TCLE) de todas as pessoas envolvidas no estudo, sendo, anteriormente, o mesmo aprovado pelo Comitê de Ética em Pesquisa (CEP) da Universidade Federal da Paraíba.

Todo o material produzido neste campo/encontro com os profissionais, gestores e usuários do CAPS foi analisado coletivamente em diferentes momentos/espaços, com diferentes atores. As produções dos encontros (narrativas, afecções, movimentos, etc.) serviram de argamassa para pôr em análise a produção do cuidado, junto com os atores nele envolvidos. Assim, o processamento/análise desse material ocorreu nos encontros cotidianos com os próprios profissionais e gestores do CAPS, reconhecendo-os como pesquisadores de seu próprio processo de trabalho/cuidado, concretizando, assim, a aposta numa pesquisa compartilhada. Estes foram pesquisadores, não no sentido da escrita deste manuscrito, mas na potência de colocarem em análise seus processos de trabalho, podendo refletir sobre o mesmo, produzindo juízos de valores e, em alguns momentos, até transformações nas suas produções de cuidado.

Este processamento/análise desses dados (produto dos encontros) teve como objetivo construir uma cartografia das redes de significações ${ }^{11}$, que produzissem novas visibilidades sobre a produção do cuidado em saúde mental naquele CAPS, buscando identificar as práticas micropolíticas do trabalho em saúde ${ }^{8}$, que forjam a produção do cuidado. A partir de então, foi possível produzir algumas narrativas sobre os novos mundos que emergiam no compartilhamento dessas várias significações, fruto dos encontros com os sujeitos envolvidos no cuidado em saúde mental.

\section{Resultados e discussão}

Nesta vivência junto ao CAPS III, emergiu, como mais expressiva dentre as significações sobre o cuidado, a prática centrada no espaço físico e simbólico do serviço, marcando a persistência de referenciais de institucionalização de pessoas com transtornos psíquicos. Tais modos de cuidado são apontados pelos próprios profissionais em reuniões de equipe com a supervisora clínico-institucional Rubi( ${ }^{(\dagger)} \mathrm{e} \quad{ }^{(\oplus)}$ Nome fictício. com os membros da pesquisa.

A possibilidade de pôr seu processo de trabalho em análise, e dar visibilidade a formas cristalizadas de operá-lo no cotidiano se apresentou como primeiro passo para a proposição de novas formas de cuidado, o que, certamente, não se 
dá de maneira mágica e repentina, mas deve propiciar um contínuo movimento de ressignificações e processamentos em educação permanente em saúde (EPS) ${ }^{12}$. Nesta direção, a educação permanente se apresenta como um importante dispositivo de reflexão sobre a prática, possibilitando a gestão compartilhada dos processos de trabalho em saúde.

Neste movimento de EPS junto à equipe do CAPS, foi possível produzir visibilidade a três movimentos por ela vivenciados que parecem refletir entraves na própria organização da RAPS no município e, mesmo, da atual conjuntura da reforma psiquiátrica no Brasil. Estes impasses se referem: à invisibilidade do território vivo na produção das redes de cuidado; ao desafio de se produzir cuidado compartilhado: o matriciamento como articulador das ações do CAPS e a atenção básica; e aos impasses para a desinstitucionalização da vida: do confinamento ao controle.

\section{A invisibilidade do território vivo na produção das redes de cuidado}

O CAPS é um serviço de base territorial. Esta é uma afirmativa comum em discursos sobre a RAPS. Mas, o que, de fato, se quer dizer com isso? Para os profissionais do CAPS III de João Pessoa, ser de base territorial implica demarcar sua vinculação a um conjunto de equipamentos e outros serviços, com vista à atenção da saúde de um grupo populacional em um dado território geográfico ${ }^{13}$.

Vale salientar que o conceito de território é apreendido de formas distintas no campo da saúde. De modo sintético, nas últimas décadas, certas formulações, utilizando saberes oriundos da geografia crítica e do planejamento e programação local de saúde, defendem abordar o território para além da noção de paisagem e ambiente fixo, de modo a desencadear ações que vão desde microlocalizar os problemas de saúde nas regiões, até definir o modo de se articularem os serviços de saúde em áreas como os distritos e certas articulações em rede ${ }^{14}$.

Autores, como Milton Santos ${ }^{15}$, por outro lado, trazem para o debate a dimensão geopolítica do território, colocando em foco a produção do território, inclusive geográfico, em relação com as produções sociais, em especial, políticas. A partir dessas críticas, esta vertente passa a buscar outras perspectivas da noção de território, deslocando o conceito, de modo a abranger os territórios que configuram as diferentes políticas de produção de subjetividade ${ }^{16}$.

Assim, é possível delimitar que o CAPS é o serviço de referência para o distrito sanitário $X$ ou $Y$, cobrindo a população dos bairros A, B e C, que são, por sua vez, assistidas pelas Unidades de Saúde da Família (USF) M, $\mathrm{N}$ e O. O CAPS deve acolher, assim, usuários de um determinado território e encaminhá-los, quando necessário, a outros equipamentos e serviços de referência a este mesmo território.

Nesta direção, o CAPS organiza seu processo de trabalho definindo miniequipes para assumirem a referência terapêutica dos usuários de diferentes territórios/bairros de sua área de abrangência. Assim, a referência terapêutica não passa pela vinculação usuário-técnico, mas por uma estratificação territorial.

Esta, sem sombra de dúvida, é uma forma de compreender a delimitação do território adscrito para uma equipe de CAPS, sustentada na lógica da organização de redes de serviços hierarquizadas. A produção de redes, neste sentido, se dá pela possibilidade de encaminhamentos de usuários para determinados serviços, implicando fluxos mais ou menos padronizados de referência e contrarreferência.

Contudo, para Saraceno ${ }^{17}$, os serviços de saúde mental devem ser compreendidos como de base comunitária, a partir da sua capacidade de produzir vínculos não apenas com serviços, mas, fundamentalmente, com a comunidade.

Um serviço de saúde mental de alta qualidade é um sistema de espaços físicos e de recursos humanos capaz de interagir com a atenção básica a saúde, outros setores do sistema sanitário, outras agências sociais e com a comunidade circundante. ${ }^{17}$ (p. 99)

Nesta perspectiva, ser de base comunitária implica trabalhar no e com o território existencial de cada indivíduo, ou seja, com seu modo de produção de vida, costurando redes de cuidado, a partir dos recursos disponíveis na vida cotidiana de cada usuário ${ }^{18}$. 
A referência do trabalho territorial vem sendo largamente abordada na atenção básica, na qual se defende a promoção da saúde a partir do acionamento das potencialidades que cada território geográfico dispõe ou pode produzir ${ }^{19}$. Neste sentido, são propostas ações de saúde na própria comunidade, o mais próximo da vida cotidiana dos usuários, articulando os recursos comunitários na produção de redes de apoio social ${ }^{20}$.

Os CAPS têm como função - assim como as equipes de saúde da família, em um dado território - ordenar redes de cuidado ${ }^{21}$, articulando os equipamentos e recursos disponíveis. Uma questão que parece crucial é pensar quais recursos são considerados, pelas equipes de CAPS, como possíveis de serem acionados. $\mathrm{Na}$ experiência acompanhada, a maioria das referências é para equipamentos públicos, em especial, da saúde, assistência social e educação. Os espaços comunitários e suas estratégias de produção de vida são, em sua maioria, invisibilizados. Os profissionais conhecem muito pouco da vida pulsante no território, no qual são referência em saúde mental. Onde há praças? Onde há grupos de mulheres ou associações comunitárias? Onde há grupos de hip-hop, grafitagem ou skate? Onde há igrejas e grupos religiosos? Onde há "boca de fumo", prostituição e violência?

Contudo, no CAPS, não existem esses mapas, nem outra forma de reconhecimento de tais territórios. Alguns profissionais que, por acaso, em sua vida "extraprofissional", circulam em alguns bairros desta área adscrita, sabem da existência de alguns desses equipamentos comunitários, mas tal conhecimento não é sistematizado, compartilhado em equipe, nem considerado no momento da proposição de estratégias terapêuticas para os usuários.

Numa reunião de equipe do CAPS, o profissional Diamante ${ }^{(g)}$ aponta a dificuldade que o serviço tem de articular o território, sobretudo com as redes informais. Ele defende a importância de se produzirem conexões/parcerias com grupos comunitários existentes nos territórios e lembra-se de um caso em que conseguiram vincular uma usuária a um grupo de capoeira. A supervisora Rubi fala da importância de a equipe conhecer os territórios e a pesquisadora RAC sugere a confecção de um mapa, semelhante aos que existem nas Unidades de Saúde da Família (USF), no qual a equipe marcaria com alfinetes as informações importantes sobre o território. Chamou a atenção que apenas poucos profissionais conheciam este tipo de estratégia de mapeamento do território e que, passados três meses após esse convite (que foi reforçado em outras reuniões), nenhum movimento foi produzido no sentido de a equipe mapear os recursos disponíveis nos territórios em que vivem seus usuários.

O desconhecimento da vida pulsante nas esquinas das casas dos usuários é de tal ordem que os profissionais não sabem dizer, sem consultar os prontuários, em que bairro vivem os usuários, ou, mesmo, a qual ESF estão vinculados. Frente a este desconhecimento, são lançadas novas inquietações ao grupo de pesquisadores trabalhadores e gestores do CAPS: Quais as implicações que tal desconhecimento traz para a produção do cuidado? Para este mesmo profissional Diamante, para efetivar a reforma psiquiátrica, é preciso inserir o usuário no mundo, "fora da RAPS". Ou seja, é preciso possibilitar que este usuário produza vida para além dos equipamentos da saúde, que possa construir trocas simbólicas nas ruas de sua cidade, exercitando a cidadania. Somente assim será possível produzir uma sociedade que incorpore a loucura como possibilidade e potência de vida, efetivando a dimensão cultural da reforma ${ }^{17}$. Porém, esse tipo de fala faz eco por parte da equipe.

Para Merhy ${ }^{8}$, a produção do cuidado só é possível quando a vida do outro tem valor. Se produção de cuidado é produção de vida, e a vida não pode estar institucionalizada em serviços de saúde, é preciso produzir redes de cuidado na (g) Nome fictício de um profissional do serviço. 
cidade, para que nela seja possível produzir vida e saúde. O cuidado, então, não pode estar circunscrito ao CAPS, como descrito por alguns profissionais que, orgulhosamente, declaram que o usuário prefere estar no serviço, pois é ali onde se sente reconhecido como sujeito, e não como "o louco". Reconhecer que a loucura é posta entre parênteses apenas nos serviços especializados em saúde mental é reconhecer, em última instância, o fracasso na efetivação de princípios da reforma psiquiátrica, como a desinstitucionalização. Pois, como apontam Alverga e Dimenstein ${ }^{6}$, apenas será possível, efetivamente, desconstruir os manicômios físicos e simbólicos, que teimam em aniquilar a existência de sujeitos com sofrimento psíquico, quando for possível produzir relações sociais que suportem a presença da diferença em sua radicalidade.

\section{O desafio de se produzir cuidado compartilhado: o matriciamento como articulador das ações do CAPS e a atenção básica}

O matriciamento é pauta em quase todas as reuniões de equipe do CAPS III. Quinzenalmente, a equipe é convocada, pela supervisora Rubi, a discutir e problematizar as ações de matriciamento nas Unidades Básicas de Saúde (UBS) do território de abrangência do CAPS. Durante estas discussões, são colocados os impasses que persistem na articulação entre os serviços substitutivos e a ESF, para a construção do cuidado compartilhado e integral.

Dentre esses impasses, os trabalhadores do CAPS apontam a falta de interesse e apropriação teórica da equipe da ESF para discutir os casos que demandam cuidado em saúde mental em seu território.

[...] a equipe de saúde da família não se mostra parceira no cuidado, e nós profissionais do CAPS nos "sujeitamos" a esta, que diz o dia e horário que podem nos receber. Quando conseguimos marcar um dia, a equipe de atenção básica mostra pouco interesse em discutir o cuidado em saúde mental [...]. (Profissional Diamante)

Buscando enfrentar esta dificuldade da Equipe de Saúde da Família (EqSF), um único profissional do CAPS assume, efetivamente, a responsabilidade pelo matriciamento das equipes da atenção básica. Sua ação visa apresentar a Rede de Atenção Psicossocial do município, para subsidiar a construção de estratégias de cuidado compartilhada entre ESF e demais estações de cuidado da RAPS. Contudo, para o conjunto dos profissionais do CAPS, mesmo com as ações de matriciamento (uma reunião de quatro horas com cada equipe da ESF do município), a atenção básica continua incapaz de produzir ou coordenar projetos terapêuticos singulares que englobem as potencialidades do território na produção do cuidado; ou, mesmo, de realizar adequadamente os encaminhamentos dos usuários aos serviços especializados da RAPS.

O matriciamento, assim como problematizado pela supervisora Rubi e pelas pesquisadoras da universidade, se justifica na medida em que o CAPS, como articulador da rede de atenção à saúde mental, deve realizar: discussões sobre os casos, intervenções conjuntas e suporte técnico-pedagógico junto com as equipes da ESF. Estas ações têm como foco principal potencializar o cuidado comunitário e a corresponsabilização dos casos existentes, aumentando a capacidade resolutiva das equipes locais frente aos problemas de saúde mental nos territórios ${ }^{22}$.

No debate da equipe sobre o matriciamento, é problematizada, pelos profissionais, sua dinâmica e a falta de envolvimento dos demais profissionais do

(h) Nome fictício de um profissional do CAPS.
CAPS. "O matriciamento deve ser visto como uma ação do CAPS, e não minha", queixa-se o profissional Ônix ${ }^{\left({ }^{(h)}\right.}$. Parece haver uma desmotivação da equipe com 
esta ação, sustentada pela afirmativa de que trata-se de um "trabalho de formiguinha", pois, mesmo com tantos esforços, a ESF continua desconhecedora da RAPS e incapaz de realizar o cuidado territorial.

Propondo um novo olhar para o matriciamento, a Rubi aponta a necessidade de o CAPS pautar uma agenda com a ESF para a discussão de casos que demandem cuidado no território. Assim, o matriciamento seria um dispositivo para a articulação de redes e cuidado compartilhado entre CAPS e ESF. Consequentemente, não seria o profissional Ônix que demandaria a participação dos demais profissionais no matriciamento, pois estes passariam a demandar, de Ônix, a articulação e agendamento das ações de matriciamento para dar encaminhamento a casos específicos.

Estas problematizações não parecem produzir eco na equipe, que parece não conseguir dar visibilidade a situações em que o CAPS demandaria da ESF a construção compartilhada de projetos terapêuticos para seus usuários, foco principal do apoio matricial ${ }^{23}$, mas já se torna um problema para Ônix, Rubi e outros profissionais, que parecem acolher tais problematizações.

Neste sentido, parece ser ainda um desafio produzir, no grande grupo, novos sentidos para o matriciamento, com vistas à efetivação da desinstitucionalização do cuidado, na medida em que implica a construção de redes de cuidado compartilhado e territorializado em saúde mental, mas, nos movimentos micropolíticos, algumas mudanças parecem ser operadas.

\section{Impasses para a desinstitucionalização: do confinamento ao controle}

Nos debates travados em equipe, alguns profissionais da equipe trazem à cena as concepções que norteiam o cuidado ofertado em saúde mental. Ônix, profissional do CAPS, ao afirmar que "[...] muitos trabalhadores da própria equipe apresentam lógicas manicomiais, e isso é difícil, porque não conseguem oferecer a assistência como preconiza as diretrizes do CAPS", convoca a todos a repensarem que cuidado é esse que está sendo produzido. E se, com o 'manicômio mental'24 ainda presente nas práticas, é possível produzir um novo modelo de cuidado.

Alguns autores ${ }^{6}$ apontam que os 'desejos de manicômio' ainda encontram-se presentes nas práticas em saúde mental. Segregar, classificar, medicalizar e controlar a vida têm sido ainda as principais formas de assistência às pessoas com transtornos mentais ${ }^{25}$. O estigma da loucura e 0 biopoder exercido nas práticas observadas/relatadas/discutidas trazem à luz os desafios para a desinstitucionalização das pessoas e a efetivação da reforma psiquiátrica.

Diante do exposto, surgem reflexões sobre quais caminhos a produção do cuidado em saúde mental tem trilhado, e em que medida a captura dada pelas lógicas manicomiais tem exercido controle sobre a vida do outro, o impedindo de percorrer novos campos existenciais e de produção de vida. A fala do profissional Diamante revela um pouco do panorama atual das práticas assumidas no CAPS: "Aqui, dentro do CAPS, tem gente que trabalha como se estivesse em um hospital psiquiátrico".

Um dos dispositivos para a superação do modelo manicomial é o Projeto Terapêutico Singular (PTS). Este tem como finalidade permitir a construção dialógica entre profissionais, usuários e familiares na construção de possibilidades de cuidado que sejam interessantes e viáveis para todos os envolvidos.

Na realidade vivenciada, a construção de PTS, muitas vezes, limita-se à oferta do cardápio de ações disponíveis no serviço. Assim, é o usuário que se adequa ao que o serviço tem a oferecer, e não o contrário, no sentido de o serviço buscar produzir ações específicas para necessidades singulares dos usuários. Nesta adequação institucionalizante, parece correr o risco do abafamento dos desejos e dos diferentes modos de subjetivação.

A equipe do CAPS, por vezes, encontra-se capturada pela rotina do serviço, limitando as ações do PTS nos espaços institucionais, desconsiderando a potencialidade do território que aquelas pessoas vivem, com vista ao cuidado em redes.

Para tanto, é fundamental considerar que a construção do PTS pressupõe o reconhecimento do território existencial do usuário e suas redes vivas de cuidado ou descuidado, assim como as linhas de fuga possíveis para a produção de novos modos de subjetivação. Saraceno ${ }^{7}$ aponta que esses projetos devem englobar estratégias de cuidado que sejam compreendidas como um processo contínuo e integrado de ações orientadas a responder as necessidades das pessoas. 
A experiência nesta pesquisa aponta para a necessidade de novas significações na construção dos PTS que esteja implicada com a circulação dos usuários nos diferentes territórios geográficos da cidade, facilitando a produção de novas redes de cuidado e de vida para o sujeito no mundo.

Talvez, assim, seja possível que, efetivamente, a loucura seja posta entre parênteses, não apenas no CAPS, mas nos diversos espaços de convivência do sujeito. Ou melhor, que a perspectiva do olhar dos trabalhadores possa extrapolar os parênteses em que ela se enquadra. Pois, mais do que usuários aprisionados em processos medicalizantes, talvez esteja aprisionada a capacidade de os profissionais perceberem e lidarem com os usuários, que, de certa forma, sempre extrapolam os parênteses, queiram os trabalhadores perceber isso ou não ${ }^{8}$.

É importante que os projetos terapêuticos facilitem a saída do usuário do serviço, sem, contudo, levar o serviço consigo, como marca de sua institucionalização. Assim, parece ser estratégico pensar em formas de transitar com o usuário na cidade sem camisas ou carros institucionais, sem blocos de carnaval ou faixas de luta antimanicomial. Sair como cidadão que circula pelas praças e bairros, que vai à praia ou parque, sem que sua vinculação institucional seja sua principal identificação social.

A medicalização, como dispositivo de controle dos corpos e da vida ${ }^{26}$, também é denunciada por alguns profissionais em seus processos de discussão do trabalho. Rubi cita uma situação que vivenciou no serviço, ao ouvir, de um profissional, que o "[...] usuário em crise só poderia ser atendido pelo médico e que a equipe não poderia atendê-lo, pois era necessário que ele fosse medicalizado". E outro profissional, Cristal, complementa assegurando que a "[...] institucionalização e medicalização dos 'doentes mentais', ainda é muito viva e presente nos serviços de saúde mental [...]".

A institucionalização seria, portanto, esse confinamento que "muitas vezes se mantém grudado ao corpo, dentro da alma" 27 (p. 71), que impede às pessoas ocuparem outros espaços. Ela transcende a estrutura física dos manicômios e é constantemente reeditada em práticas manicomializantes nos diversos serviços de saúde. Superar tal controle implica o reconhecimento e efetivação da diversidade de modos de existência e a sua circulação na cidade, produzindo trocas simbólicas que permitam conexões de vida. Nesta direção, o cuidado seria:" A construção de outros projetos de vida que não dependam exclusivamente dos serviços, que consiga escapar das práticas tutelares sem desassistir e criar fluxos de encaminhamentos que de fato efetivem uma rede de assistência"28 (p. 197).

Mas, como produzir autonomia para que o sujeito possa circular pela cidade quando o cuidado se confunde com tutela? Duas cenas chamam atenção sobre isso: A primeira ocorre na avaliação da Marcha da Loucura realizada na semana de Luta Antimanicomial, em que os profissionais reclamaram da falta de banheiros químicos. Relataram precisar solicitar, para os usuários, o uso de banheiros aos lojistas da cidade. Mas por que os usuários não solicitaram, eles mesmos, o uso dos banheiros? Por que sua relação com os lojistas precisa ser mediada pelo profissional? Estariam os profissionais emprestando seu poder contratual ${ }^{7}$ aos usuários na negociação do acesso aos espaços públicos? Ou subestimando a capacidade de os mesmos exercerem tal contratualidade? A segunda cena se passa no refeitório do CAPS no horário do lanche, quando um profissional precisa ficar numa janelinha que separa a cozinha do refeitório, retirando um copo de suco e um sanduiche e entregando-os nas mãos dos usuários. Porque, novamente, essa mediação do profissional? Por que os usuários não seriam capazes de se servirem sozinhos?

A partir destas cenas, problematizamos que os serviços de saúde mental compõem, na maioria das vezes, a cena de um território existencial do usuário, participando de alguma forma de sua vida e das suas relações, desempenhando um certo papel na vida do mesmo. Estes papéis, por sua vez, podem ser de apoio à expansão de redes vivas, ampliando e enriquecendo as suas relações e experiência, ou podem favorecer o empobrecimento das redes de apoio do usuário, funcionando a partir do exercício de certo controle e cristalização de papéis, despotencializando a vida e a produção de linhas de fuga do sujeito.

Nesse sentido, apostamos que a mobilização dos profissionais aos recursos do território junto aos usuários, pode modificar os fluxos das relações de poder, fazendo-o junto com estes. Istopor sua vez, não impede que os usuários possam fazê-lo sozinhos, mas, em momentos, é necessário que os profissionais exerçam seu poder e emprestem-no para que os usuários acessem banheiros, lojas, ou outros locais, até que as proibições sejam vencidas. 
Merhy ${ }^{9}$ traz, para o debate, o tema da tutela, apontando que, em todo cuidado, há uma dimensão tutelar. Contudo, este autor explicita que esta tutela pode, ao mesmo tempo, aprisionar o sujeito ou libertá-lo para o caminhar na vida, já que: "o mesmo lugar, ocupado pela interdição, é também espaço de encontro autopoiético" (p. 3).

Assim, a tutela autonomizadora no seu modo de agenciar uma libertação a partir de si, busca, a todo instante, produzir movimento no qual o agir vivo de um dispara produção de vida no outro. Por outro lado, a tutela que gera dependência tem um efeito castrador nas possibilidades produtivas do sujeito perante sua vida.

Por isso, é fundamental estar atento ao paradoxo - do aprisionamento e da libertação - que envolve o ato de cuidar, de modo que o cuidado não aprisione o sujeito, mas, pelo contrário, o possibilite caminhar pela vida.

Entendemos que este cuidado emancipador e enriquecedor da vida provoca a desterritorialização/ reterritorialização do trabalhador, a todo momento, na produção do cuidado, uma vez que este exige dos mesmos se recolocarem no encontro com o outro, se metamorfoseando cotidianamente nas suas práticas e relações com os usuários e todos os atores do território.

\section{Considerações finais}

A produção de encontros e narrativas junto ao CAPS III, para cartografar modos de produção do cuidado na RAPS em João Pessoa, permitiu problematizar algumas dificuldades vivenciadas por profissionais e gestores do serviço em se territorializar no mundo vivo dos seus usuários ${ }^{10}$. Ser um serviço de base territorial deve significar muito além de estar num determinado espaço geográfico, mas pertencer a certo mundo, habitado por pessoas que produzem modos de existir singulares.

A efetivação da desinstitucionalização do cuidado em saúde mental passa pela possibilidade do trânsito do usuário na rua, sem o sobrenome do serviço em sua identidade: Ser João, simplesmente, e não João usuário do CAPS. Nesta reinvenção de novos modos de cuidado, pode-se questionar: Como produzir novos processos de trabalho que possibilitem a invenção de modos de cuidados que trasbordem a estrutura física dos CAPS, de tal forma que não caibam dentro de seus muros institucionais todas as suas ofertas terapêuticas? Como possibilitar que territórios comunitários sejam cenários para oficinas terapêuticas ofertadas pelo CAPS, permitindo que o usuário viva a cidade e esta reconheça a presença cotidiana da loucura em suas ruas, praças e cantos? Talvez nesse movimento, de se abrir ao mundo vivo da cidade, a saúde mental possa produzir cuidados para além do sofrimento psíquico, se ocupando com a produção de vida das pessoas.

\section{Colaboradores}

Thayane Pereira da Silva Ferreira e Juliana Sampaio realizaram a escrita do artigo, participaram ativamente da análise e discussão dos resultados, revisão e aprovação da versão final do trabalho. Adelle Conceição do Nascimento Souza, Dilma Lucena de Oliveira e Luciano Bezerra Gomes contribuíram com a redação do artigo, discussão sobre os resultados e revisão final da escrita. 


\section{Referências}

1. Ministério da Saúde (BR). Reforma psiquiátrica e política de saúde mental no Brasil. Documento apresentado à Conferência Regional de Reforma dos Serviços de Saúde mental: 15 anos depois de Caracas. Brasília (DF): Ministério da Saúde; 2005.

2. Alves PCB. A fenomenologia e as abordagens sistêmicas nos estudos sócioantropológicos da doença: breve revisão crítica. Cad Saude Publica. 2006; 22(8):1547-54.

3. Ministério da Saúde (BR). Portaria n 336-02, de 19 de fevereiro de 2002. Dispõe sobre a definição e estabelecimento de diretrizes para o funcionamento dos Centros de Atenção Psicossocial. Brasília (DF): Ministério da Saúde; 2002.

4. Barros JO, Mângia EF. Rede social e atenção às pessoas com transtornos mentais: novo desafio para os serviços de saúde mental. Rev Ter Ocup Univ Sao Paulo. 2007; 18(3):135-42.

5. Guatarri F, Rolnik S. Micropolítica: cartografia do desejo. Petrópolis: Vozes; 1996.

6. Alverga AR, Dimenstein M. Reforma psiquiátrica e os desafios para a desintitucionalização da loucura. Interface (Botucatu). 2006; 10(20):299-316.

7. Saraceno B. Libertando identidades: da reabilitação psicossocial à cidadania possível. Rio de Janeiro: Instituto Franco Basaglia; 1999.

8. Merhy EE. Saúde: a cartografia do trabalho vivo. 3a ed. São Paulo: Hucitec; 2002.

9. Merhy EE. Cuidado com o cuidado em Saúde: saiba explorar seus paradoxos para defender a vida. [Internet]. 2004 [citado 12 Dez 2015 ]. Disponível em: http://www.uff. $\mathrm{br} /$ saudecoletiva/professores/merhy/capitulos-09.pdf.

10. Gomes MPC, Merhy EE. Pesquisadores in-mundos: um estudo da produção de acesso e barreira em saúde mental. Porto Alegre: Editora Rede Unida; 2014.

11. Rolnik S. Cartografia sentimental: transformações contemporâneas do desejo. São Paulo: Estação Liberdade; 1989.

12. Merhy EE, Feuerwerker LCM, Ceccim RB. Educación permanente en salud: una estrategia para intervenir en la micropolítica del trabajo en salud. Salud Colect. 2006; 2(2):147-60.

13. Mendes EV. As redes de atenção à saúde. Cienc Saude Colet. 2010; 15(5):297-305.

14. Paim JS. Desafios para a saúde coletiva no século XXI. Salvador: EDUFBA; 2006.

15. Santos M, organizador. Território: globalização e fragmentação. 4a ed. São Paulo: Hucitec; 1998.

16. Guattari F, Rolnik S. Micropolítica: cartografias do desejo. 7a ed. Petrópolis: Vozes; 2005.

17. Saraceno B. Reabilitação psicossocial: uma estratégia para a passagem do milênio. In: Pitta A, organizador. Reabilitação psicossocial no Brasil. 2a ed. São Paulo: Hucitec; 2001. p. 13-8.

18. Martó JB. La vulnerabilidad relacional: análisis del fenômeno y pautas de intervención. Redes - Rev Hisp Anal Redes Soc [Internet]. 2006 [citado 12 Dez 2016]. Disponível em: http://revistaredes.rediris.es/.

19. Ministério da Saúde (BR). Portaria no 3.088, de 23 de dezembro de 2011. Institui a Rede de Atenção Psicossocial para pessoas com sofrimento ou transtorno mental e com necessidades decorrentes do uso de crack, álcool e outras drogas, no âmbito do Sistema Único de Saúde (SUS). Brasília (DF): Ministério da Saúde; 2011.

20. Martins RM. A relevância do apoio social na velhice. Millenium (Rev ISPV) [Internet]. 2005 [citado 10 Maio 2015]; 31. Disponível em: https://repositorio.ipv.pt/ handle/10400.19/429. 
21. Ministério da Saúde (BR). Saúde mental no SUS: os centros de atenção psicossocial. Brasília (DF): Secretaria de Atenção à Saúde/DAPE; 2004.

22. Ministério da Saúde (BR). Secretaria de Atenção à Saúde. Departamento de Atenção Básica. (Cadernos de Atenção Básica, n 39.) Brasília (DF): Ministério da Saúde; 2014.

23. Campos GWS, Domitti AC. Apoio matricial e equipe de referência: uma metodologia para gestão do trabalho interdisciplinar em saúde. Cad Saude Publica. 2007; 23(2):399-407.

24. Pelbart PP. Manicômio mental: a outra face da clausura. In: Lancetti A, organizador. Saúde e loucura 2. São Paulo: Hucitec; 1990. p. 130-8.

25. Machado LD, Lavrador MCC. Loucura e subjetividade. In: Machado LD, Lavrador MCC, Barros MEB, organizadores. Texturas da psicologia: subjetividade e política no contemporâneo. São Paulo: Casa do Psicólogo; 2001. p. 45-58.

26. Foucault M. Vigiar e punir. Petrópolis: Vozes; 1984.

27. Baptista LA. Narrações contemporâneas: vagabundos e turistas nas práticas da saúde mental. In: Jacó-vilela AM, Cerezzo AC, Rodrigues HBC, organizadores. Clio-Psyché hoje: fazeres e dizeres psi na história do Brasil. Rio de Janeiro: Relume Dumará, Faperj; 2001. p. 71-84.

28. Amorim AKMA, Dimenstein M. Desinstitucionalização em saúde mental e práticas de cuidado no contexto do serviço residencial terapêutico. Cienc Saude Colet. 2009; 14(1):195-204.

Ferreira TPS, Sampaio J, Souza ACN, Oliveira DL, Gomes LB. La producción del cuidado en salud mental: desafíos más allá de los muros institucionales. Interface (Botucatu). 2017; 21(61):373-84.

El artículo presenta algunas problematizaciones sobre los desafíos de la desinstitucionalización en el cuidado de salud mental con base en un Centro de Atención Psicosocial (CAPS) de João Pessoa, Brasil. La dirección metodológica fue dada en el cotidiano del servicio, en el cual los investigadores participaban en las reuniones de equipo y acompañaban la producción del cuidado dentro y fuera del CAPS. En el proceso de educación permanente, juntamente con el equipo del CAPS, fue posible proporcionar visibilidad a tres movimientos: la invisibilidad del territorio vivo en la producción de las redes de cuidado, la necesidad de la organización matricial como articuladora de las acciones del CAPS y la atención básica y, por último, los callejones sin salida para la desinstitucionalización de la vida. Sin embargo, nuestra apuesta fue en el sentido de que en el movimiento de abrirse al mundo vivo de la ciudad, la salud mental consiga producir cuidados que vayan más allá del sufrimiento síquico, ocupándose con la producción de vida de las personas.

Palabras clave: Desinstitucionalización. Salud mental. Reforma psiquiátrica.

Submetido em 18/03/16. Aprovado em 24/06/16. 